\title{
Facile and Surfactant-Free Synthesis of Hierarchical ZnO Microstructures
}

\author{
Kezhen $\mathrm{Qi}^{1 *}$, Ruidan Wang ${ }^{2}$, Jiaqi $\mathrm{Fu}^{3}, \mathrm{Ke} \mathrm{Chen}^{4}$ and Chunying Zuo ${ }^{5}$
}

${ }^{1}$ College of Chemistry and Life Science, Shenyang Normal University, Shenyang, 110034, China, ${ }^{2}$ The Department for Discipline and Scientific Research, Shenyang Normal University, Shenyang, 110034, China, ${ }^{3}$ College of Chemistry and Molecular Engineering, Peking University, Beijing 100871, China, ${ }^{4}$ The School of Teacher Education, Shenyang Normal University, Shenyang, 110034, China, ${ }^{5}$ The Science College of Heilongjiang Bayi Agricultural University, Daqing, 163319, China. *Email: qikezhen2003@gmail.com.

\begin{abstract}
Hierarchical $\mathrm{ZnO}$ crystals with flower-like microstructures were successfully synthesized via a facile hydrothermal route without using any surfactants. The morphology of these microstructures can be easily controlled by adjusting the $\mathrm{pH}$ of the reaction solution. The products were characterized by X-ray powder diffraction (XRD) and scanning electron microscope (SEM). Furthermore, a possible growth mechanism of $\mathrm{ZnO}$ hierarchical microstructures was proposed.
\end{abstract}

Keywords: Zinc oxide; Hierarchical microstructures; Hydrothermal synthesis; Free-surfactant.
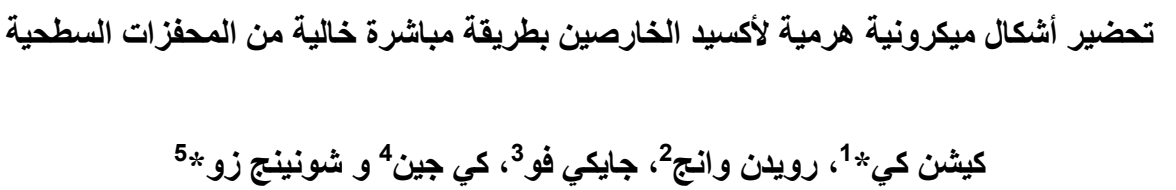

ملخص: بلورات ZnO الهرمية ذات التركيب الميكروبي الزهري تم تحضير ها بنجاح بواسطة المسار الحراري المائي السهل وبدون استخدام أية

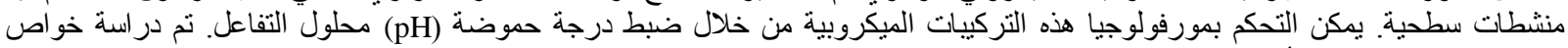

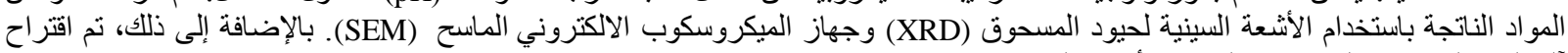

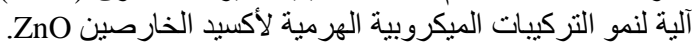

مفتاح الكلمات: أكسيد الخارصين، التركيات الميكروبية الهرمية، التحضير الحراري المائي، بدونـ منشطات سطحية.

\section{Introduction}

$\mathbf{I}^{\mathbf{n}}$

n the past few decades, hierarchically structured materials have attracted a great deal of attention because they provide a potential opportunity to explore the utility of their novel properties [1]. Synthesis of these hierarchical structures with controlled size and quality is surely significant to tune their physical properties, and will help to further broaden their application. Hydrothermal synthesis is regarded as the mainstream morphology-controlled synthetic method, because it is easy to control the shape and size of the materials produced. However, there are some drawbacks of the original method, especially in the use of toxic surfactants [2]. Moreover, these surfactants are difficult to remove, and appropriate solvents are usually needed to wash them off. Thus, morphology-controlled synthesis of well aligned hierarchical structures via a simple, surfactant-free method is of great importance.

Zinc oxide $(\mathrm{ZnO})$, as an important semiconductor material, has been extensively investigated because of its great potential applications in electronics, photoelectronics, optics, sensors and catalysis [3-7]. These applications result from its unique properties, which depend not only on the phase but also on the morphology and organization. For instance, Ko et al. reported that $\mathrm{ZnO}$ nanowires present high efficiency in dye-sensitized solar cells [8]. Arya et al. demonstrated that $\mathrm{ZnO}$ crystals exhibit different biosensor properties corresponding to their different shape changes [9]. Up to now, many different $\mathrm{ZnO}$ nano/micro nanostructures have been reported [10-15]. However, to develop a facile, environment-friendly method to synthesize $\mathrm{ZnO}$ crystals with well defined complex morphology is still a major challenge.

Herein, we present a facile hydrothermal method for synthesis of hierarchical $\mathrm{ZnO}$ microstructures without using any surfactant. The effects of the solution's $\mathrm{pH}$ on the morphology of the $\mathrm{ZnO}$ crystal were systemically 


\section{KEZHEN QI ET AL}

investigated. Furthermore, a possible growth mechanism of the $\mathrm{ZnO}$ hierarchical microstructures is proposed on the basis of the experimental results.

\section{Experimental section}

\subsection{Sample preparation}

The $\mathrm{ZnO}$ microflowers were synthesized by a simple hydrothermal process. In a typical synthesis procedure, $0.744 \mathrm{~g} \mathrm{Zn}\left(\mathrm{NO}_{3}\right)_{2} \cdot 6 \mathrm{H}_{2} \mathrm{O}$ and $0.6 \mathrm{~g} \mathrm{NaOH}$ were dissolved in a reaction solution containing $15 \mathrm{~mL}$ ethanol and $20 \mathrm{~mL}$ water under vigorous stirring for $10 \mathrm{~min}$. Then, the above mixture was transferred to a $30 \mathrm{~mL}$ Teflon-lined stainless steel autoclave and heated at $120{ }^{\circ} \mathrm{C}$ for $24 \mathrm{~h}$. The autoclave was taken out and allowed to cool naturally to room temperature. The as-prepared product was separated by centrifugation, washed several times with distilled water and ethanol, respectively, and finally dried at $60^{\circ} \mathrm{C}$ in air for $5 \mathrm{~h}$.

\subsection{Characterization of the samples}

The XRD patterns of the products were collected on a Rigaku D/max 2500V/PC X-ray diffractometer with $\mathrm{Cu}-$ $K_{\alpha}$ radiation $\left(\lambda=1.5406 \AA\right.$ ), employing a scanning rate of $0.017^{\circ} \mathrm{s}^{-1}$. The morphology of the as-synthesized products was examined by field emission scanning electron microscope (FE-SEM, JEOL JSM-6700F).

\section{Results and discussion}

\subsection{Morphology and structure of the $\mathrm{ZnO}$ products}

Figure 1a shows the XRD pattern of the prepared $\mathrm{ZnO}$ hierarchical microstructures. All diffraction peaks can be indexed to the hexagonal wurtzite structure of ZnO (JCPDS No. 36-1451). No other noticeable peaks of impurities are detected, which indicates a high purity of the prepared $\mathrm{ZnO}$. The morphologies of the product were examined by SEM. Figure 1b shows a typical SEM image of the $\mathrm{ZnO}$ microflowers, constructed of interleaved thin plates or nanosheets. The microflowers are about $2 \mu \mathrm{m}$ in diameter.
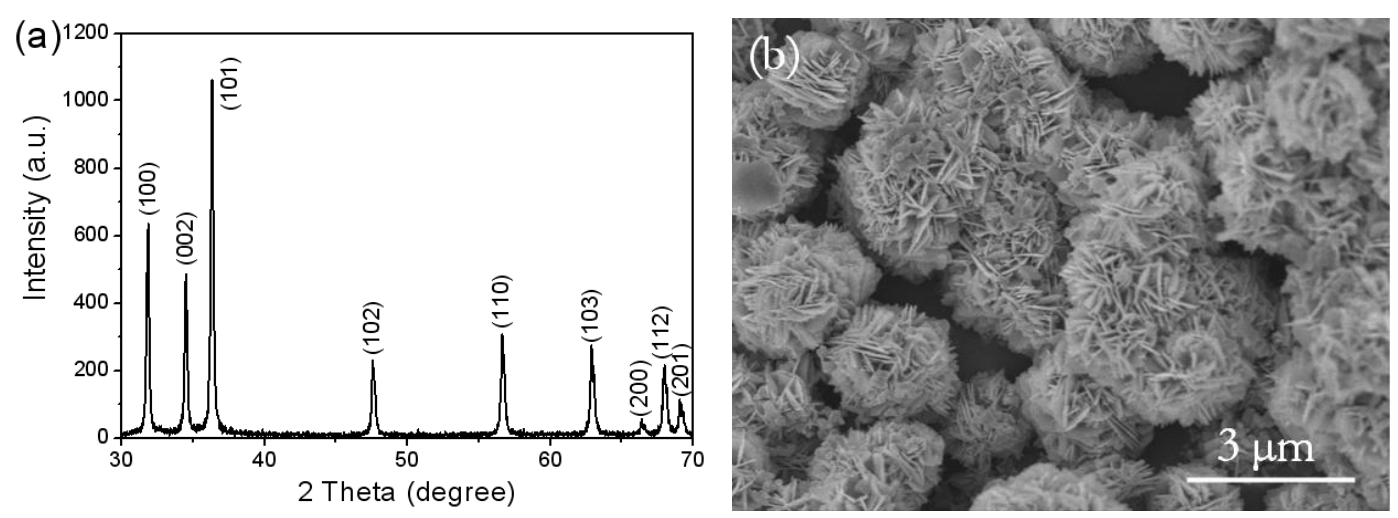

Figure 1. Characterization of the $\mathrm{ZnO}$ samples obtained when the $\mathrm{pH}$ of the reaction solution is 13.8: (a) $\mathrm{XRD}$ pattern and (b) SEM image.

\subsection{Effects of solution's pH on the morphology of $\mathrm{ZnO}$ crystals}

In this section, we report our results of the $\mathrm{pH}$ effects on the morphology of $\mathrm{ZnO}$ crystals. When the $\mathrm{pH}$ of the solution is 13.1, the product is composed of nanoparticles about 200-400 nm in diameter (Figure 2a). When the $\mathrm{pH}$ of the solution is increased to 13.6 , nanoplates with a size of $150-350 \mathrm{~nm}$ are synthesized (Figure $2 \mathrm{~b}$ ). When the $\mathrm{pH}$ of the solution is further increased to 13.7, the formed nanosheets become thinner and gather together to form flowerlike microstructures (Figure 2c). These complex structures are made of nanosheets which grow continuously from one layer to another in a helical fashion. The above experimental results show that the solution's $\mathrm{pH}$ has a strong influence on the morphology of $\mathrm{ZnO}$ crystals.

The possible growth mechanism of $\mathrm{ZnO}$ microflowers is illustrated in Figure 3. First, $\mathrm{Zn}^{2+}$ and $\mathrm{OH}^{-}$can react easily and lead to fast nucleation and congregation, resulting in sphere-like cores, which would probably provide high-energy sites for crystalline primary particles to grow. Then a secondary growth stage could occur at the protuberances of the primary particle and grow into the nanopetals, finally forming the flower-like hierarchitectures. 

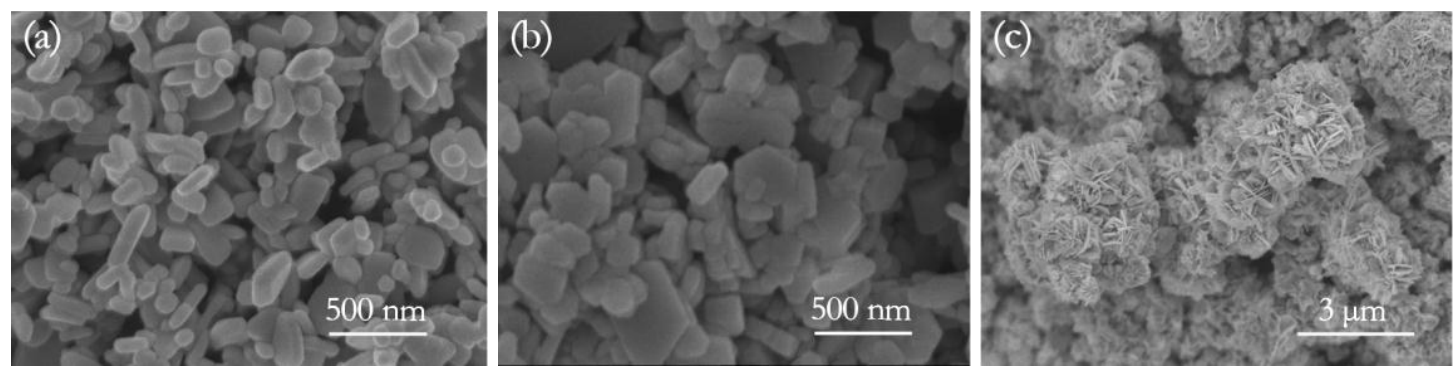

Figure 2. SEM images of $\mathrm{ZnO}$ samples obtained with different $\mathrm{pH}$ values of the reaction solution.

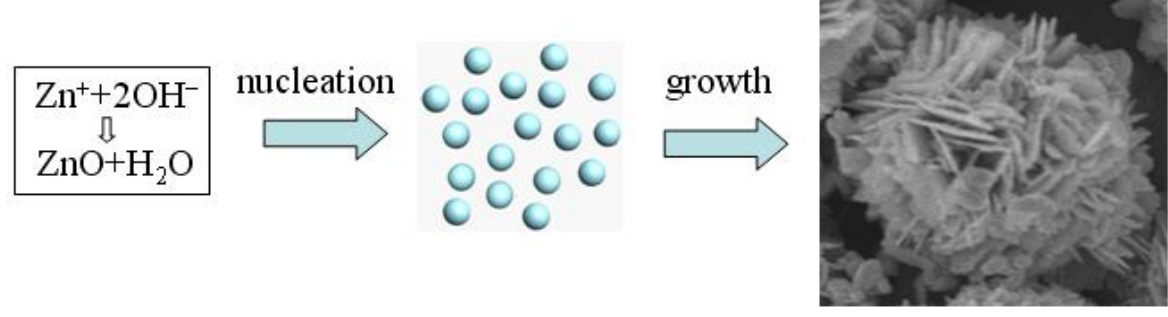

Figure 3. Illustration of the possible growth mechanism of the $\mathrm{ZnO}$ microflowers.

We also changed the zinc source to $\mathrm{Zn}\left(\mathrm{CH}_{3} \mathrm{COO}\right)_{2} \cdot 2 \mathrm{H}_{2} \mathrm{O}$ to study the effect of the precursor on the morphology of $\mathrm{ZnO}$ crystals (Fig. 4). When the $\mathrm{pH}$ of the solution is 13.1, nanoplates with varying sizes are formed (Fig. 4a). When the $\mathrm{pH}$ of the solution increases to 13.6, nanoplates with size of 500-600 nm are synthesized (Fig. 4b). When the $\mathrm{pH}$ of the solution is increased to 13.7 (Fig. 4c), microflowers with diameter of 2-4 $\mu \mathrm{m}$ are observed. The morphology of the $\mathrm{ZnO}$ crystals is slightly different from that resulting from using $\mathrm{Zn}\left(\mathrm{NO}_{3}\right)_{2} \cdot 6 \mathrm{H}_{2} \mathrm{O}$ as the zinc source, but the $\mathrm{pH}$ effects on the shape evolution are similar in that, as the $\mathrm{pH}$ value increases, the shape transforms from the nanosheet to the microflowers.
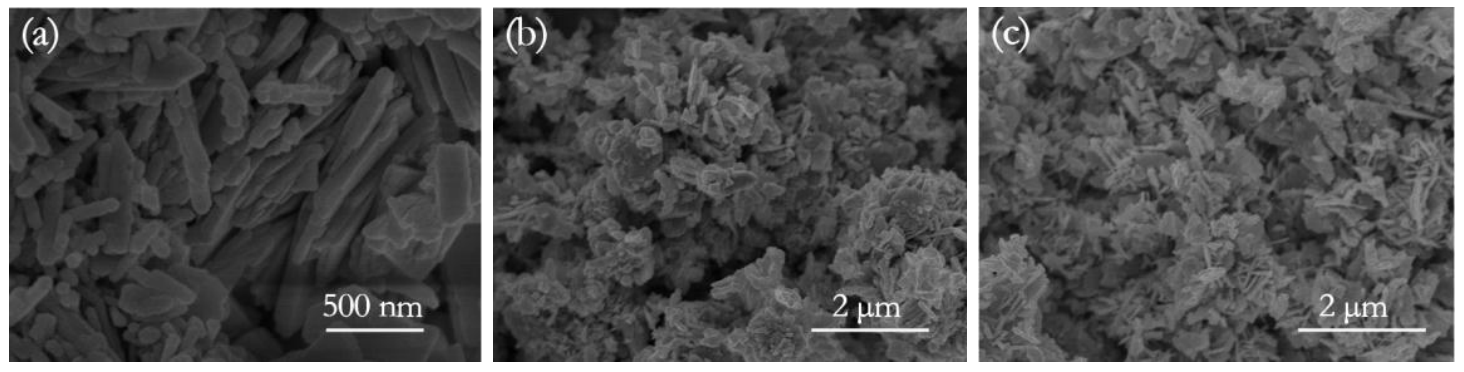

Figure 4. SEM images of $\mathrm{ZnO}$ crystals obtained by using $\mathrm{Zn}\left(\mathrm{CH}_{3} \mathrm{COO}\right)_{2} \cdot 2 \mathrm{H}_{2} \mathrm{O}$ as the zinc source with different $\mathrm{pH}$ values of the reaction solutions: (a) 13.1, (b) 13.6, (c) 13.7 .

\section{Conclusion}

Hierarchical $\mathrm{ZnO}$ microstructures were successfully synthesized via a facile hydrothermal route. The $\mathrm{pH}$ of the solution plays an important role in determining the final morphology of these microstructures. Based on these results, a possible growth mechanism of the hierarchical $\mathrm{ZnO}$ microstructures has been proposed. This simple route is expected to enable the fabrication of other metal oxides with hierarchical microstructures.

\section{Acknowledgment}

This work was supported by Financial Support from Shenyang Normal University (Grant No. 05455440109035). 


\section{KEZHEN QI ET AL}

\section{References}

1. Qi, K.Z., Yang, J.Q., Fu, J.Q., Wang, G.C., Zhu, L.J. and Zheng, W.J. Morphology-controllable ZnO rings: ionic liquid-assisted hydrothermal synthesis, growth mechanism and photoluminescence properties. Cryst. Eng. Comm., 2013,15, 6729-6735.

2. Jung, S., Cho, W., Lee, H.J. and Oh, M. Self-template-directed formation of coordination-polymer hexagonal tubes and rings, and their calcination to $\mathrm{ZnO}$ rings. Angew. Chem. Int. Ed., 2009, 48, 1459-1462.

3. Zhang, J., Sun, L., Yin, J., Su, H., Liao, C. and Yan, C. Control of ZnO morphology via a simple solution route. Chem. Mater., 2002, 14, 4172-4177.

4. Gao, P.X. and Wang, Z.L. Mesoporous polyhedral cages and shells formed by textured self-assembly of ZnO nanocrystals. J. Am. Chem. Soc., 2003, 125, 11299-11305.

5. Wang, X.D., Summers, C.J. and Wang, Z.L. Large-scale hexagonal-patterned growth of aligned ZnO nanorods for nano-optoelectronics and nanosensor arrays. Nano Lett., 2004, 4, 423-426.

6. Lao, J.Y., Wen, J.G. and Ren, Z.F. Hierarchical ZnO nanostructures. Nano Lett., 2002, 2, 1287-1291.

7. Kurtz, M., Strunk, J., Hinrichsen, O., Muhler, M., Fink, K., Meyer, B. and Wöll, C. Active sites on oxide surfaces: ZnO-catalyzed synthesis of methanol from $\mathrm{CO}$ and $\mathrm{H}_{2}$. Angew. Chem., Int. Ed., 2005, 44, 27902794.

8. Ko, S.H.,Lee, D.,Kang, H.W., Nam, K.H.,Yeo, J.Y.,Hong, S.J.,Grigoropoulos, C.P. and Sung, H.J. Nanoforest of hydrothermally grown hierarchical $\mathrm{ZnO}$ nanowires for a high efficiency dye-sensitized solar cell. Nano Lett., 2011, 11, 666-671.

9. Arya, S.K.,Saha, S.,Ramirez-Vick, J.E., Gupta, V., Bhansali, S. and Singh, S.P. Recent advances in ZnO nanostructures and thin films for biosensor applications: review. Anal. Chim. Acta., 2012, 737, 1-21.

10. Zhai, T., Li, L., Ma, Y., Liao, M.,Wang, X., Fang, X.,Yao, J., Bando, Y. and Golberg, D. One-dimensional inorganic nanostructures: synthesis, field-emission and photodetection. Chem. Soc. Rev., 2011, 40, 2986-3004.

11. Peng, Y., Xu, A.W., Deng, B., Antonietti, M. and Cölfen, H. Polymer-controlled crystallization of Zinc oxide hexagonal nanorings and disks. J. Phys. Chem. B., 2006, 110, 2988-2993.

12. Boal, A.K., Ilhan, F., DeRouchey, J.E., Thurn-Albrecht, T., Russell, T.P. and Rotello, V.M. Self-assembly of nanoparticles into giant spherical arrays. Nat., 2000, 404, 746-749.

13. Shi, R.X., Yang, P.,Wang, J.R., Zhang, A.Y., Zhu, Y.N., Cao, Y.Q. and Ma, Q. Growth of flower-like ZnO via surfactant-free hydrothermal synthesis on ITO substrate at low temperature. Cryst. Eng. Comm., 2012, 14, 5996-6003.

14. Wen, M.W.,Yang, B.F.,Yan, H.W., Fu, Z.P., Cai, C., Liu, K.P., Chen, Y.J., Xu, J., Fu, S.Q. and Zhang, S.Y. Morphology-controlled synthesis of flowerlike $\mathrm{ZnO}$ nano/microstructures and their photocatalytic property. $J$ Nanosci. Nanotechnol., 2009, 9, 2038-2044.

15. Cauda, V., Pugliese, D., Garino, N., Sacco, A., Bianco, S., Bella, F., Lamberti, A. and Gerbaldi, C. Multifunctional energy conversion and storage electrodes using flower-like Zinc oxide nanostructures. Energy, 2014, 65, 639-646. 